doi https://doi.org/10.31977/grirfi.v22il.2757

Recebido: 14/12/2021 | Aprovado: 18/02/2022

Received: 12/14/2021 | Approved: 02/18/2022

\title{
NOTAS SOBRE O MISTICISMO RACIONAL DE ERWIN SCHRÖDINGER
}

\author{
Raoni Wohnrath Arroyo ${ }^{1}$ \\ Universidade Estadual de Campinas (UNICAMP) \\ (D) https://orcid.org/0000-0002-3800-8505>. \\ E-mail: raoniarroyo@gmail.com
}

William Davidans Sversutti ${ }^{2}$

Universidade Federal do Paraná (UFPR),

https://orcid.org/0000-0003-2740-768X

E-mail: williamsversutti@gmail.com

\section{RESUMO:}

Frequentemente referido como um dos "pais da mecânica quântica", o pensamento de Erwin Schrödinger foi popularizado pelas suas contribuições na física contemporânea. No entanto, tal pensador contribuiu para a discussão acerca dos limites do pensamento filosófico e da fundamentação última da realidade, principalmente nos seus escritos tardios. O presente artigo aborda tais discussões, tendo como fio condutor a noção schrödingeriana de 'consciência' e as implicações éticas de tal concepção.

PALAVRAS-CHAVE: Erwin Schrödinger; Ética; Metafísica; Misticismo; Unicidade da consciência.

\section{NOTES ON ERWIN SCHRÖDINGER'S RATIONAL MYSTICISM}

\begin{abstract}
:
Often referred to as one of the "founding fathers of quantum mechanics", Erwin Schrödinger's thoughts were popularized by his contributions to contemporary physics. However, this thinker contributed to the discussion about the limits of philosophical thought and the ultimate foundation of reality, especially in his later writings. This article addresses such discussions, having as a guideline the Schrödingerian notion of 'consciousness' and the ethical implications of such a conception.
\end{abstract}

KEYWORDS: Erwin Schrödinger; Ethics; Metaphysics; Mysticism; Unity of consciousness.

\footnotetext{
${ }^{1}$ Doutor(a) em Filosofia pela Universidade Federal de Santa Catarina (UFSC), Florianópolis - SC, Brasil. Pesquisador(a) pósdoutoral no Centro de Lógica, Epistemologia e História da Ciência da Universidade Estadual de Campinas (UNICAMP), Campinas - SP, Brasil. Apoio: processo no 2021/11381-1, Fundação de Amparo à Pesquisa do Estado de São Paulo (FAPESP), São Paulo SP, Brasil. Membro da International Network on Foundations of Quantum Mechanics and Quantum Information, grupo de Florianópolis - SC, Brasil. Pesquisador do Grupo de Pesquisa em Lógica e Fundações da Ciência do Conselho Nacional de Desenvolvimento Científico e Tecnológico (CNPq), Brasil.

2 Doutorando(a) em Filosofia na Universidade Federal do Paraná (UFPR), Curitiba- PR, Brasil. O presente trabalho foi realizado com apoio da Coordenação de Aperfeiçoamento de Pessoal de Nível Superior (CAPES), Brasil - Código de Financiamento 001.
}

ARROYO, Raoni Wohnrath; SVERSUTTI, William Davidans. Notas sobre o misticismo racional de Erwin Schrödinger. Griot : Revista de Filosofia, Amargosa - BA, v.22 n.1, p.215-226, fevereiro, 2022. 


\section{Introdução}

Pouco abordada na literatura, a metafísica desenvolvida nos escritos tardios de Erwin Schrödinger (1964) oferece uma ontologia monista que percorre diversos problemas filosóficos clássicos, como o problema mente-corpo. Neste breve estudo, limitaremos a discussão acerca da questão da multiplicidade das consciências-tese que Schrödinger se posiciona contrariamente, sendo que é precisamente esse posicionamento que revela as influências místicas do monismo ontológico que propõe, e que possui consequências no âmbito da ética. Abordamos muito brevemente a concepção do termo "consciência" na metafísica schrödingeriana sob a luz, principalmente, do estudo de Hans Poser (1992). Em seguida, buscamos explicitar as influências filosóficas na literatura mística que levaram Schrödinger a formular sua visão de mundo, aludindo, principalmente, aos estudos de William James (2002) e Caroline Murr (2014). Finalmente, delineamos algumas implicações éticas da metafísica monista desenvolvida por Schrödinger (1964), referindo novamente o estudo de Poser (1992).

Ainda que a exposição contida neste estudo seja sucinta e de caráter esquemático, buscamos apresentar, sempre que possível, indicações para leituras mais específicas sobre os assuntos discutidos. Dessa forma, o presente estudo tem como objetivo especificar os debates sobre assuntos pouco abordados na literatura, e que, ao que parece, de extrema riqueza filosófica. Schrödinger considera que a metafísica não faz parte do conhecimento, mas é seu suporte, sem o qual nenhuma elaboração seria possível, chegando a afirmar até mesmo que a metafísica se torna física ao longo de seu desenvolvimento.

Para tanto, este artigo é estruturado da seguinte forma. Um dos aspectos centrais de seu modelo metafísico é a negação da tese da multiplicidade das mentes. O comprometimento ontológico com a existência de uma única consciência é também próprio da escola de pensamento (darśana) do Advaita Vedānta: todas as mentes individuais (subjetivas) são manifestações de uma única Mente. Esse é o assunto da seção 1. A influência do Vedānta no pensamento de Schrödinger (sobretudo nos seus escritos tardios) é notável e amplamente reconhecida até mesmo pelo próprio Schrödinger, quem considera que a multiplicidade das mentes seria uma aparência ao passo que a unicidade da mente seria real. Schrödinger reconhece, no entanto, que tal debate não se daria no campo da razão dedutiva, discursiva, o que caracteriza tal posição como uma metafísica essencialmente mística. Esse é o assunto da seção 2. Bertotti utiliza o termo "misticismo racional" para classificar tal tipo de atitude, identificada em pensadores como Erwin Schrödinger e Albert Einstein, que abertamente afirmam que o "existente" é um todo, e sua unidade pode ser apreendida intuitivamente (e não somente de forma racional) —e que, ainda assim, o fazem em conexão com o trabalho filosófico e científico (racional por definição). Schrödinger utiliza a metafísica advaita-vedantina como referencial ontológico para seu projeto científico e filosófico, e não como autoridade religiosa; isto é, utiliza desse referencial para argumentar em favor de sua proposta, de modo que constrói um modelo aberto a críticas e não um dogma incontestável. De tal concepção metafísica acerca da noção de "consciência" emerge uma concepção ética. A transição de uma metafísica individualista da consciência para uma metafísica unitiva tem uma notável implicação ética: o altruísmo. Isto é, em uma concepção monista na qual todos os seres na verdade são a mesmo e único Ser, as noções de "competitividade" e "rivalidade" são cada vez menos significativas. Esse é o assunto da seção 4.

\section{Uma ontologia da consciência na metafísica schrödingeriana}

Pensador austríaco do século XX, Erwin Rudolf Josef Alexander Schrödinger (1987-1961) é conhecido principalmente por seus trabalhos na física, mais especificamente na mecânica 
quântica (onde talvez uma das mais populares contribuições seriam as reflexões suscitadas pelo experimento mental do gato de Schrödinger). No entanto, como aponta Vinicius Silva (2001, p. 175), pouco se refere - ao menos no Brasil—sobre a metafísica que desenvolve em seus escritos tardios, sobretudo nas obras "Mein Leben, meine Weltansicht", que fora traduzida para o idioma inglês como "My View of the World" (cf. SCHRÖDINGER, 1964)—e que, traduzida livremente para o português, significaria "Minha Visão de Mundo"—e "O que é vida?", que há tradução em português (cf. SCHRÖDINGER, 1997).

Um dos aspectos centrais de seu modelo metafísico é a negação da tese da noção da multiplicidade de "consciências" (termo frequentemente intercambiável na literatura selecionada por "mente"). Schrödinger (1964, p. 18) considera que os debates em relação ao conceito de consciência ou mente enfrentam uma situação problemática expressa pelos intermináveis debates acerca de resoluções para o problema mente-corpo (cf. ROBINSON, 2020) cuja encarnação mais recente na mecânica quântica foi a de trocar o problema da medição pelo problema mente-corpo na esperança de elucidar um problema nos fundamentos da física contemporânea (cf. HALL; KIM; MCELROY; SHIMONY, 1977, p. 761), nomeadamente, o problema da medição em mecânica quântica (cf. WIGNER, 1983). Muito brevemente, a mecânica quântica descreve a evolução de estados físicos por superposições (e.g., somas), mas detecta estados únicos (i.e., não somas); o problema da medição é dizer como e porque isso acontece (cf. COHEN-TANNOUDJI; DIU; LALOE, 1991). Uma das soluções é dizer que a consciência de observadores humanos causa a transição de soma de estados para estados únicos (cf. WIGNER, 1983); com isso, o problema mente-corpo entra em cena: como podemos entender a interação entre as consciências causais postuladas por certas posturas na filosofia da física e os sistemas físicos? Para Hall, Kim, McElroy e Shimony, (1977, p. 761), o raciocínio é o seguinte:

[...] se [o problema de medição] apresenta um problema genuíno, então é um problema muito difícil, e alguns físicos e filósofos passaram a acreditar que nenhuma solução fácil e não radical terá sucesso. Uma vez que o problema mente-corpo é um problema perene não resolvido (que a física clássica de alguma forma conseguiu contornar sem resolver), podese conjeturar que os dois problemas estão interligados. ${ }^{3}$ (HALL; KIM; MCELROY; SHIMONY, 1977, p. 761).

Para Schrödinger (1964, p. 18), o problema ocorre devido ao frequente comprometimento ontológico com a existência de múltiplas mentes: "para a filosofia [...] a dificuldade real está na multiplicidade espacial e temporal de observadores e indivíduos cognoscentes. Se todos os eventos ocorressem em uma consciência, a situação seria extremamente simples"4 Pode-se perceber na passagem anteriormente citada, assim como em diversas outras (cf. COHEN, 1992), o comprometimento ontológico com a existência de uma única mente que, conforme observa Bertotti (1985, p. 91), é própria do pensamento do Vedānta, uma das diversas escolas de pensamento da Índia:

O enigma das consciências individuais e sua comunidade levaram ele [Schrödinger] a uma posição, característica da filosofia indiana, que é o fundamento filosófico do clássico Vedanta: todas as mentes individuais [...] são manifestações de uma única Mente que abrange tudo. ${ }^{5}$ (BERTOTTI, 1985, p. 91, ênfase nossa).

\footnotetext{
3 Tradução nossa.

4 Tradução nossa.

5 Tradução nossa.
} 
Sobre o termo "Vedānta", destacamos um trecho de uma exposição de George Conger (1944, p. 239) que explicita precisamente o aspecto metafísico do Vedānta, conforme abordado na discussão acima:

[...] a filosofia central dos Upanixades e do Vedānta, muitas vezes considerada panteísta, seria descrita com maior precisão como um monismo espiritualista. Exemplo melhor de panteísmo é apresentado pelo Deus de Espinosa com um número infinito de atributos. No Advaita Vedānta, Brahman é caracterizada por sat (ser), cit (inteligência) e ānanda (bemaventurança), ao invés de uma gama de atributos pessoais; [...] Brahman é alcançada pelo indivíduo que chega a compreender sua própria identidade com a Realidade Una. ${ }^{6}$ (CONGER, 1944, p. 239).

Altamente influenciado pelo pensamento do Vedānta (cf. BITBOL, 2004, p. 171; COHEN, 1992), Schrödinger (1997, p. 100) faz uso da o termo sânscrito "māyā", que corresponde à distinção-bastante antiga também na filosofia grega-entre o que é real e o que é aparente para responder à questão da multiplicidade das mentes:

A única alternativa possível consiste apenas em reter da experiência imediata que a consciência é um singular cujo plural é desconhecido; que existe apenas uma coisa e o que parece ser uma pluralidade é apenas uma série de aspectos diferentes dessa mesma coisa, produzidos por um engano (o termo indiano MAYA). A mesma ilusão é produzida em uma galeria de espelhos e, do mesmo modo, Gaurisankar e o monte Everest acabam por ser o mesmo cume visto de vales diferentes. (SCHRÖDINGER, 1997, p. 100, ênfase original).

Gough (1981, p. 237) aponta que "a doutrina de māyā, ou a irrealidade do dualismo sujeito/objeto, bem como a irrealidade da pluralidade de almas e seu ambiente, é a vida da filosofia indiana primitiva". ${ }^{7}$ Assim, não se remete exclusivamente ao Vedānta. Ainda assim, conforme Bertotti (1985), a influência do pensamento tardío de Schrödinger $(1964 ; 1997)$ seria primordialmente o Vedānta, destacamos apenas seu uso dentro do sistema vedantino. De acordo com Radhakrishnan (1914, p. 431), o termo " $m \bar{a} y \bar{a}$ " se insere no sistema vedantino da seguinte forma:

[...] apenas o Absoluto, chamado Brahman, é real e as manifestações finitas são ilusórias. Há apenas uma realidade absoluta e indiferenciada, cuja natureza é constituída pelo conhecimento. O mundo empírico é inteiramente ilusório, com suas distinções de mentes finitas e objetos e os objetos de seu pensamento. Sujeitos e objetos são como imagens fugazes que englobam a alma que sonha, e que se reduzem a nada no momento em que acordam. O termo "māyā" significa o caráter ilusório do mundo finito. [...] Os aspectos centrais da filosofia Vedantina, como é concebida atualmente, são resumidamente explicitados nas seguintes frases: Brahman é o real e o universo é falso, /O Atman [termo que designa a "alma individual"] é Brahman. Nada mais. ${ }^{8}$ (RADHAKRISHNAN, 1914, p. 431).

Desta forma, a multiplicidade das mentes seria uma aparência, ao passo que a unicidade da mente seria real ou, nas palavras de Cohen (1992, p. 97-98), “não existe 'realmente' uma multiplicidade de eus. [...] existe uma unidade de todas as consciências"9. Schrödinger haveria debatido tal questão-por mais que considerasse aparente—com Carnap. Para uma exposição

\footnotetext{
6 Tradução nossa.

7 Tradução nossa.

8 Tradução nossa.

9 Tradução nossa.
} 
detalhada desse debate ver Bitbol (2004). Schrödinger (1964, p. 18, ênfase nossa) reconhece, no entanto, que tal debate não se daria no campo da razão lógico-dedutiva, conforme explicita na seguinte passagem: "eu não penso que essa dificuldade possa ser resolvida logicamente, através de um pensamento consistente, em nossos intelectos. [...] a pluralidade que percebemos é apenas aparente, não é real"10. De forma mais enfática, Schrödinger (1964, p. 95) explicita que tal ideia, própria do pensamento do Vedanta, é essencialmente mística:

Resumidamente, é a visão de que todos nós, seres vivos, somos unidos na medida em que somos, na verdade, lados ou aspectos de um único ser, que talvez na terminologia ocidental possa ser chamado de "Deus" enquanto nos Upanixades seu nome é "Brahman". [...] Nós reconhecemos que estamos lidando aqui não com algo logicamente dedutível, mas com metafísica mística. ${ }^{11}$ (SCHRÖDINGER. 1964, p. 95, ênfase nossa).

Uma das principais características do misticismo é a alegada percepção direta da unidadequalitativamente diferente da especulação filosófica acerca de tal unidade -, que William James (2002) classifica como "experiência mística".

\section{Intuição e supra intelectualidade: a via mística}

James (2002, p. 322) afirma que a experiência mística frequentemente aponta em direção a uma posição filosófica, a saber, o monismo. Isso ocorre devido à natureza de unidade da experiência, expressa na indistinção entre o indivíduo que tem a experiência e o Absoluto que, para James (2002, p. 324), é uma das grandes conquistas do misticismo:

A superação de todas as barreiras usuais entre o indivíduo e o Absoluto é a grande conquista mística. Em estados místicos, ao mesmo tempo, nos tornamos Um com o Absoluto e temos consciência de nossa unidade. Essa é a triunfante e duradoura tradição mística, dificilmente alterada por diferenças de região ou credo. ${ }^{12}$ (JAMES, 2002, p. 324).

Poser (1992, p. 163) classifica a metafísica schrödingeriana como um "monismo idealista dinâmico", cuja expressão máxima se encontra na expressão sânscrita "tat tvam asi", que Aldous Huxley (1947, p. 8) traduz para o inglês como "That art thou", que traduzido livremente para o português significaria algo como "tu és Isto", e que Schrödinger (1964, p. 22) interpreta como: "Eu estou no leste e no oeste, eu estou abaixo e acima, eu sou o universo todo"13. James (2002, p. 325) adiciona, enfatizando ainda mais o caráter monista da ontologia expressa através da experiência mística: “'Tu és Isto!', dizem os Upanixades, e os Vedantinos acrescentam: ‘Não uma parte, não um modo de ser Isto, mas idêntico a Isto, o Espírito absoluto do Mundo" ${ }^{14}$

Ken Wilber (1977, p. 152) vai além e considera que tal unidade é empírica:

A psicologia vedantina funda-se na introvisão experimentalmente verificável de que Brahman-Atman é a única Realidade, e sua preocupação primária consiste em proporcionar uma explicação pragmática do "por que" os seres humanos não compreendem sua básica e suprema identidade com Brahman. Em geral, a cega aceitação, pelos humanos, de dualismos e distinções é a ignorância (avidyā) que os fazem pousar diretamente num mundo de ilusões $(m \bar{a} y \bar{a}) .{ }^{15}$ (WILBER, 1977, p. 152).

\footnotetext{
10 Tradução nossa.

11 Tradução nossa.

12 Tradução nossa.

13 Tradução nossa.

14 Tradução nossa.

15 Tradução nossa.
} 
Schrödinger (1997) é explícito a esse respeito:

Desde os primitivos grandes Upanixades, no pensamento indiano, a identificação de ATHMAN = BRAHMAN (o eu pessoal iguala-se ao eu eterno, e onipresente e onisciente), longe de constituir uma blasfêmia, representava a quintessência da mais profunda intuição quanto aos acontecimentos do mundo. O maior empenho de todos os estudiosos da escola Vedanta era, após o aprendizado dos movimentos dos lábios para a pronúncia correta, realmente assimilar em suas mentes este pensamento, o mais grandioso de todos. De novo, os místicos de muitos séculos, independentemente, mas em perfeita harmonia uns com os outros (algo como ocorre com as partículas em um gás ideal) descreveram, cada um deles, a experiência única de sua vida em termos que podem ser resumidos na expressão: DEUS FACTUS SUM (Tornei-me Deus). (SCHRÖDINGER, 1997, p. 98, ênfase original).

Como observa Caroline Murr (2014, p. 212), o referido sentimento de "unidade" pode ser alcançado por diversas vias. James (2002, p. 310) destaca o ioga como uma dessas vias, com uma série de técnicas bastante específicas para o alcance da experiência mística:

Na Índia, o treino na intuição mística ficou conhecido desde tempos imemoriais sob o nome de "yoga". "Yoga" significa a união experimental do indivíduo com o divino. É baseado em exercícios perseverantes; e dieta, postura, respiração, concentração intelectual [meditação], e uma disciplina moral que varia ligeiramente nos diferentes sistemas que o ensinam. ${ }^{16}$ (JAMES, 2002, p. 310).

Haveria, no entanto, limites para a transmissão linguística do conteúdo suscitado pela experiência mística. Ainda que exista a possibilidade de atingi-la, a possibilidade de comunicá-la é ainda mais problemática. James (2002, p. 314) considera que a incomunicabilidade da união do indivíduo com o Absoluto é um dos aspectos centrais do misticismo: "a verdade mística existe para o indivíduo que se transportou, mas para ninguém mais. Nisso, como disse, assemelha-se ao conhecimento que nos é dado através das sensações mais do que naquele que é fruto de um pensamento conceitual". ${ }^{17}$

Para Huxley (1947, pp. 147-148), isso ocorre pois a linguagem e o misticismo (ou a "filosofia perene") se tratam de aspectos temporais diferentes:

A matéria da Filosofia Perene é a natureza da Realidade espiritual eterna; mas a linguagem em que ela precisa ser formulada foi desenvolvida com o propósito de tratar dos fenômenos no tempo. Eis aí por que, em todas as formulações, encontramos um elemento de paradoxo. Não se descreve a natureza da Verdade-Fato por meio de símbolos verbais que não correspondem adequadamente a ela. Na melhor das hipóteses, pode-se indicá-la na linguagem de non sequiturs e contradições. ${ }^{18}$ (HUXLEY, 1947, pp. 147-148).

Assim, como observa James (2002, p. 314), "é um lugar comum na metafísica que o conhecimento de Deus não pode ser discursivo, mas deve ser intuitivo [...]". ${ }^{19} \mathrm{O}$ termo "intuição" para Henri Bergson (2006, pp. 27-29), significa a "procura imediata do eterno", o que ocorre por uma "faculdade supra intelectual":

\footnotetext{
16 Tradução nossa.

17 Tradução nossa.

18 Tradução nossa.

19 Tradução nossa.
} 
Quão mais instrutiva seria uma metafísica realmente intuitiva, que seguisse as ondulações do real! [...] Não começaria por definir ou descrever a unidade sistemática do mundo. Quem sabe se o mundo é efetivamente uno? Apenas a experiência poderá dizê-lo e a unidade, caso exista, aparecerá ao termo da procura como um resultado; impossível de pô-la de saída como princípio. Será, aliás, uma unidade rica e plena, a unidade de uma continuidade, a unidade de nossa realidade [...]. (BERGSON, 2006, pp. 27-29, ênfase nossa).

Tallapragada Row, Helena Blavatsky, e Damodar Mavalankar (1923, pp. 282-283) endossam a tese da incomunicabilidade da experiência mística (referida como "iluminação") dentro das tradições místicas (referidas como uma "ciência oculta"):

Na Ciência Oculta os segredos não podem ser transmitidos subitamente, mediante uma comunicação escrita, nem mesmo oral. Se assim fosse, tudo que os 'Irmãos' teriam que fazer seria publicar um Manual de Instruções que poderia ser ensinado nas escolas, ao lado da gramática [...]. A verdade é que, até que o neófito atinja a condição necessária para aquele grau de Iluminação para o qual ele está qualificado e apto, a maior parte dos segredos, se não todos eles, é incomunicável. A iluminação deve partir de dentro. ${ }^{20}$ (BLAVATSKY; MAVALANKAR. 1923, pp. 282-283, ênfase nossa).

Em Platão (cf. Carta VII) também haveria um indicativo para tal ideia, principalmente numa tradição chamada "indireta". Na metafísica de Platão (Carta VII, 341b) as "coisas maiores (tà mégista)" não seriam, de acordo com a chave de leitura da Escola de Tübingen, não seriam conteúdo dos Diálogos, mas estariam contidos nas "doutrinas não-escritas (ágrapha dógmata)". Tais "coisas maiores" se referiram aos graus ontológicos mais altos da metafísica platônica, tal como as discussões acerca do Uno, causa do Sumo Bem. Sobre tais coisas, diz Platão (Carta VII, $341 b-341 d)$ :

[...] de maneira alguma o conhecimento dessas coisas [as coisas maiores] é comunicável como o dos outros conhecimentos, mas, depois de muitas discussões feitas sobre elas, e depois de uma vida comum, subitamente, como luz que se acende de uma faísca, ele nasce na alma e alimenta-se de si mesmo. (PLATÃO, 2008, Carta VII, 341b-341d).

Maria Pereira (1990, pp. XXIX-XXX) comenta tal aspecto da metafísica platônica da seguinte maneira:

[...] o mundo visível (horata ou doxasta) tem em primeiro lugar uma zona de eikones ("imagens", ou, como outros preferem, "ilusão"). Num nível mais elevado, temos todos os seres vivos (zoa) e objetos do mundo, conhecidos através de pistis (fé). O mundo inteligível (noeta) tem também dois sectores proporcionais a estes, o inferior e o superior, o primeiro apreendido através da diánoia ("entendimento" ou "razão discursiva") e o segundo só pela nóesis ("inteligência" ou "razão intuitiva"). PEREIRA (1990, pp. XXIXXXX, ênfase original).

Em todos os casos parece haver uma hierarquia ontológica, na qual os graus mais altos da metafísica não são acessíveis à razão e, em especial, à razão discursiva, tal como parece ser o caso da experiência mística que, como pontua James (2002, p. 323), “é supra-luzente, supra-esplendente, supra-essencial, supra-sublime, supra tudo que pode ser nomeado". ${ }^{21}$

\footnotetext{
20 Tradução nossa.

21 Tradução nossa.
} 


\section{Um misticismo racional: o uso filosófico da tradição}

Para Murr (2014, p. 212), a metafísica schrödingeriana, justamente por ter uma estreita relação com seu trabalho científico, não deve ser entendida como um aspecto religioso, mas essencialmente filosófico; Poser (1992, p. 161, ênfase nossa) vai além e aponta que sua proposta filosófica é mais do que uma continuação de seu trabalho científico: "talvez seja mais adequado enxergar a posição ontológica de Schrödinger na física como um resultado de suas reflexões filosóficas" ${ }^{22}$. Para Schrödinger (1964, p. 5, ênfase nossa), a "[...] metafísica não faz parte do edifício do conhecimento, mas é seu suporte, sem o qual nenhuma construção futura é possível. Talvez possamos dizer até mesmo que a metafísica se transforma em física no curso de seu desenvolvimento" 23 .

Poser (1992, p. 166) destaca ainda que Schrödinger (1964) utiliza a metafísica vedantina como referencial ontológico para seu projeto científico e filosófico, e não como autoridade religiosa; isto é, utiliza da discussão presente no Vedānta para argumentar em favor de sua proposta, de modo que constrói um modelo aberto a críticas e não um dogma incontestável.

Bertotti (1985, p. 83) utiliza o termo "misticismo racional" para classificar tal tipo de atitude, identificada em pensadores como Schrödinger e Albert Einstein:

\footnotetext{
No desenvolvimento da física teórica durante o segundo trimestre deste século $[\mathrm{XX}]$ podese reconhecer, creio eu, a influência de uma visão de mundo particular que poderia ser chamado de "misticismo racional" [...] [na qual] o "existente" é um todo, e sua unidade pode ser apreendido intuitivamente. ${ }^{24}$ (BERTOTTI, 1985, p. 83).
}

No entanto, a ligação deste aspecto de seu pensamento, caracterizado como "misticismo racional" (cf. Bertotti, 1985; Cohen, 1992) é obscura. Cohen (1992, p. 98) acredita que a ausência de uma ligação se dá pela posição de schödingeriana de que a ciência deve ser fundamentalmente objetiva, isto é, deve excluir de forma preliminar o sujeito que conhece daquilo que é conhecido. Isso ocorreria pelo princípio nomeado por Schrödinger (1997) de "Princípio de objetivação":

Por objetivação, estou me referindo àquilo que também é frequentemente chamado de a "hipótese do mundo real" ao nosso redor. Defendo que equivale a uma crta simplificação que adotamos para dominar o problema infinitamente intricado da natureza. Sem estar ciente dele e sem ser rigorosamente sistemático com ele, excluímos o Sujeito Cognoscente do domínio da natureza que nos esforçamos por entender. Retrocedemos para o papel de um espectador que não pertence ao mundo, o qual, por esse mesmo procedimento, tornase um mundo objetivo. (SCHRÖDINGER, 1997, p. 132).

Schrödinger (cf. Cohen, 1992, p. 99) não defenderia uma ideia de ciência subjetiva, como em alguns sistemas metafísicos, tampouco objetiva à maneira do empirismo moderno: mas impessoal. Para Murr (2014, p. 25), "esse princípio consiste, basicamente, em estabelecer a dualidade entre sujeito e objeto", motivo pelo qual nomeia de "mundo objetivado" o construto científico na obra de Schrödinger. Por outro lado, Murr (2014, pp. 205-206) nomeia de "pósobjetivada" a metafísica schrödingeriana, na qual a "meta é alcançar um estado de homogeneidade de consciências, inspirando-se na ontologia Vedanta". Para Murr (2014, p. 207):

Esse título nos pareceu adequado pois nossa interpretação é a de que Schrödinger tem de fato o objetivo de chegar a um estado de coisas transformado, através do processo de base

\footnotetext{
22 Tradução nossa.

23 Tradução nossa.

24 Tradução nossa.
} 
mística que leva à unificação de mentes, corpos, sujeitos e objetos. Não se trataria, nesse caso, de uma reconstrução racional em direção a uma abstração, mas sim de uma legítima busca pela unidade. (MURR, 2014, p. 207).

O modo pelo qual Schrödinger (1964) culmina em sua construção metafísica não deve ser perdido de vista: conforme destacado por Murr (2014, p. 211):

\begin{abstract}
Para Schrödinger, os processos que produzem a manifestação do mundo (que podemos fazer corresponder à objetivação) são os mesmos que associam-se diretamente à consciência. Desde que relacionados ao aprendizado de algo novo, esses processos ocorrem nos organismos vivos como um todo, não apenas em cérebros. O que não havíamos comentado ainda são as consequências desse raciocínio: ao considerarmos os organismos vivos como um todo, isto é, todos juntos como que formando uma unidade, chegamos à unidade das suas consciências através de uma argumentação científica. Logo, podemos dizer que Schrödinger usa as explicações científicas para justificar a adoção da doutrina hindu da identidade das consciências. (MURR, 2014, p. 211).
\end{abstract}

Ou seja, é partindo das suas reflexões científicas que Schrödinger (1964, p. x) chega às reflexões metafísicas que, por sua vez, ressignificam retroativamente suas concepções científicas anteriores.

\title{
A emergência de implicações éticas
}

Própria de uma visão de mundo, da concepção ontológica acerca da noção de "consciência" emerge uma concepção ética. Isto é, uma vez aceita a transição de uma metafísica individualista da consciência para uma metafísica unitiva, uma notável implicação ética aparece como consequência: o altruísmo ou, dito de outro modo, uma ética que não é centrada em indivíduos.

Em uma concepção monista na qual todos os seres na verdade são a mesmo e único Ser, as noções de "competitividade" e "rivalidade" são cada vez menos significativas. Talvez uma das implicações mais expressivas tenha sido sistematizada pelo próprio Vedānta, com o conceito sânscrito de "ahimsā", que é comumente traduzido para o português como "não violência", indicando a falta de sentido ontológico em causar sofrimento a um ser (visto que tal ação voltarse-ia como "causar sofrimento ao Ser").

Como aponta Poser (1992, p. 159), tal concepção metafísica tem implicações ainda mais radicais: num modelo materialista (ou dualista), a ética é associada ao plano mental, que ou é irrelevante (no caso da metafísica materialista, que é comprometida com a tese epifenomenalista de que a mente é reduzida aos arranjos materiais) ou é relegado ao subjetivismo (no caso da metafísica dualista calcada no cogito).

\footnotetext{
Normas, valores e responsabilidade pertencem ao domínio do mental. E se todas as consciências são essencialmente uma, isso tem consequências diretas para a ética, já que tal unidade nos permite caracterizar ações como moralmente boas, independentemente do indivíduo. Para Schrödinger, este é o ponto mais importante, pois permite atribuição de significado à vida, algo que não seria possível somente com apoio das ciências empíricas. ${ }^{25}$ (POSER, 1992, p. 159).
}

Schrödinger alegadamente se queixa de que existe, no âmbito científico, uma tendência a esquecer de que toda a ciência é indissociável das produções culturais da humanidade. Um construto metafísico também o seria. Talvez seu monismo idealista dinâmico de Schrödinger seja,

25 Tradução nossa. 
como sugere Poser (1992, p. 166) muito incisivo para as concepções vigentes na filosofia da mente, o materialismo (um tipo reducionista de monismo) e o dualismo; talvez, para essas correntes metafísicas, o comprometimento ontológico com a existência de uma única consciência poderia parecer absurdo.

\section{Considerações finais}

Procuramos apresentar, ainda que de passagem, a forma como a metafísica elaborada por Schrödinger (1964)—uma visão de mundo—se constitui, também, pelo uso referencial de aspectos da literatura mística, especificamente do monismo indiano representado pelo Vedānta.

De um ponto de vista prático, permanece questionável se uma metafísica idealista, como a de Schrödinger (1964), poderia ser integrada à ciência contemporânea-mesmo que tal resposta permaneça em aberto como um papel para a história. Ainda assim, os aspectos da metafísica schrödingeriana que destacamos aqui mereceriam, como sugere Poser (1992, p. 166), ser levados em consideração justamente pelo seu viés ético, isto é, da tentativa de construir visão de mundo baseada em reflexões éticas.

Nessa perspectiva, a proposta de Schrödinger (1964), ao combinar a racionalidade científica com elementos supra intelectuais do Vedānta como elementos filosóficos, teria seu mérito na configuração de uma tentativa válida para apresentar uma alternativa às metafísicas materialistas e dualistas que, por sua vez, são bastante utilizadas para guiar pesquisas científicas - e nas quais a ética não tem sua relevância ancorada na própria metafísica da qual emerge. 


\section{Referências}

BERTOTTI, Bruno. "The later work of E. Schrödinger". Studies in History and Philosophy of Science Part A, vol. 16, n. 2, pp. 83-100, 1983.

BITBOL, Michel. "The problems of other minds: a debate between Schrödinger and Carnap". Phenomenology and the Cognitive Science, vol. 3, n. 1, pp. 115-123, 2004.

COHEN, Robert S. "Some Notes on Schrödinger and Mysticism". Em: BITBOL, Michel; DARRIGOL, Olivier (Eds.). Schrödinger: Philosophy and the Birth of Quantum Mechanics, pp. 95100. Gif-sur-Yvette, Editions Frontieres, 1992.

CONGER, George P. "Eastern and Western Metaphysics". Em: MOORE, Charles A. Philosophy: East and West, pp. 236-247. Princeton: Princeton University Press, 1944.

GOUGH, Archibald E. The Philosophy Of The Upanishads And Ancient Indian Metaphysics. London: Kegan Paul, 1891.

HALL, Joseph; KIM, Christopher; MCELROY, Brien; SHIMONY, Abner. Wave-Packet Reduction as a Medium of Communication. Foundations of Physics, vol. 7, n. 9/10, pp. 759-767, 1977.

MARIA PEREIRA, Helena. Platão, A República: Introdução, tradução do grego e notas. Lisboa: Fundação Calouste Gulbenkian, 1990.

MURR, Caroline E. A Realidade Através Do Espelho: Schrödinger E Russell No País Da Objetivação. 2014. 323 p. Tese (Doutorado em Filosofia). Florianópolis: Universidade Federal de Santa Catarina, 2014.

MURR, Caroline E. Fúsica Quântica E Objetividade Científica: Algumas Ideias Filosóficas De Erwin Schrödinger. 2010. 162 p. Dissertação (Mestrado em Filosofia). Florianópolis: Universidade Federal de Santa Catarina, 2010.

PLATÃO. Carta VII. Tradução de José Trindade dos Santos e Juvino Maia Jr. Rio de Janeiro: Loyola/PUC-Rio, 2008.

POSER, Hans. "The Notion Of Consciousness In Schrödinger's Philosophy Of Nature". Em: GÖTSCHL, Johann (Ed.). Erwin Schrödinger's World View: The Dynamics Of Knowledge And Reality, pp. 153-168. Kluwer Academic Publishers, 1992.

RADHAKRISHNAN, Sarvepalli. "The Vedanta Philosophy and the Doctrine of Maya". International Journal of Ethics, pp. 431-451, vol. 24, n. 4, 1914.

ROBINSON, Howard. "Dualism". Em: ZALTA, Edward N. (Ed.), The Stanford Encyclopedia of Philosophy. Stanford: Metaphysics Research Lab, Stanford University, 2020. Disponível em: $<$ https://plato.stanford.edu/archives/fall2020/entries/dualism/>. Acesso: 08/10/2021.

SCHRÖDINGER, Erwin R. J. My View of the World. Cambridge: Cambridge University Press, 1964.

SCHRÖDINGER, Erwin R. J. O que é vida? O aspecto físico da célula viva seguido da Mente e matéria e Fragmentos autobiográficos. Tradução de Jesus de Paula Assis e Vera Yukie Kuwajima de Paula Assis. São Paulo: Fundação da Editora da UNESP, 1997.

SILVA, Vinicius C. “A Filosofia da Natureza de Erwin Schrödinger”. Ensaios Filosóficos, Vol 4, pp. 167-184, 2011.

BERGSON, Henri. O pensamento e o movente: ensaios e conferências. São Paulo, Martins Fontes, 2006.

JAMES, William. The Varieties of Religious Experience: A Study in Human Nature. London, Routledge, 2002.

ROW, Tallapragada G. S.; BLAVATSKY, Helena P.; MAVALANKAR, Damodar K. The Mahatma Letters To A. P. Sinnett. London, T. Fisher Unwin, 1923. 
WIGNER, Eugene. Remarks On The Mind-Body Question. Em: WHEELER, John; ZUREK, Wojciech (Eds.). Quantum Theory and Measurement, pp. 168-181. Princeton: Princeton University Press, 1983.

Contribuição dos(as) autores(as) / Author's Contributions:: Raoni Wohnrath Arroyo e William Davidans Sversutti participaram da pesquisa, discussão e redação do artigo. Ambos aceitaram e aprovaram a versão final do texto. Uma versão preliminar deste artigo foi apresentada por RWA no X Simpósio de Filosofia da Universidade Estadual de Maringá, 2015, sob o título de "Misticismo racional e a dimensão ética da metafísica de Erwin Schrödinger". O presente artigo se beneficiou dos comentários feitos pela audiência na ocasião da apresentação.

Autor(a) para correspondência / Corresponding author: Raoni Wohnrath Arroyo. raoniarroyo@gmail.com 